\title{
Royal college warns against "unsound tests" for infertility
}

\section{FDA issues advice to women taking HRT} to run the treatment centres, including two companies from the United Kingdom, two from the United States, two from South Africa, and one company from Canada.

Organisations representing health professionals were concerned that the treatment centres could destabilise the NHS by poaching staff. A spokesman for the Department of Health, however, said that contracts would not allow poaching and that staff would have to come from overseas or the independent sector. The only NHS staff used would be staff seconded to centres at the request of purchasers.

Susan Mayor London

\section{Implementation of clinical governance is patchy, report says}

The concept of clinical governance in the NHS, whereby patients take centre stage and staff learn from their mistakes to improve the quality of care, is starting to reap benefits for patients, although some trusts are doing better than others, says a report.

According to the National Audit Office three quarters of trusts in England can identify specific improvements in patient care that have grown out of clinical governance. However, the overall implementation of clinical governance is patchy, with large variations between and within trusts, it says in its report.

The review shows that most of the elements needed for clinical governance, such as reporting of adverse incidents, information for patients, and clinical risk management, are in place in most trusts. But the will to change the culture of the NHS was often lacking.

Zosia Kmietowicz London

$\overline{\text { Achieving Improvements through Clini- }}$ cal Governance: Progress Report on Implementation by NHS Trusts is accessible at www.nao.gov.uk
The US Food and Drug Administration, together with the Department of Health and Human Services and the National Institutes of Health, has launched an educational campaign to inform women about the risks and benefits of postmenopausal hormone replacement therapy (HRT).

The US Congress directed the FDA to develop information material after a number of studies found that HRT was associated with an increased risk of developing certain conditions, including breast cancer (JAMA 2002;288:321-3) and heart disease (New England Journal of Medicine 2003;349:523-34).

The material comprises a fact sheet on menopause and HRT and a pocket guide with discussion points to be used to prompt women to discuss the matter with their healthcare providers. The agency has also set up a website (www.fda.gov/womens/ menopause)

The fact sheet urges women who take HRT to take the lowest dose for the shortest amount of time and to discuss the matter with their doctor.

Deborah Josefson Nebraska

\section{Dutch government} introduces swingeing cuts to health spending

The centre right Dutch coalition announced this week that it intended to make big cuts in health spending, which would end the country's place as one of the top three spenders on health care in Europe. It is to reduce spending by $€ 2.3 \mathrm{bn}$ ( $£ 1.6 \mathrm{bn}$; $\$ 2.6 \mathrm{bn})$ a year, out of a health budget of $€ 41 \mathrm{bn}$, in an attempt to slow the apparently inexorable rise in health spending.

The Royal Dutch Medical Association said that the economies would be "disastrous" and were "bad for patients and bad for doctors."

Tony Sheldon Utrecht
Debashis Singh London

Women seeking answers on the internet for their fertility problems are being misled by being offered clinical investigations and treatments that lack any sound scientific basis, says a review published this week by the scientific advisory committee of the Royal College of Obstetricians and Gynaecologists.

The review addressed the hypothesis that some cases of reproductive failure (failure to conceive or carry a pregnancy to term) might be caused by immunological abnormalities. Although many of these tests are routinely offered to patients in clinics and are available on the internet, they have so far not been properly validated in well designed research.

The review examined the evidence for a battery of immunological tests, namely antiphospholipid antibody; thyroid antibody; ovarian antibody; antinuclear antibody; and antisperm antibodies.

The authors also looked at tests of natural killer cells and shared parental human leukocyte antigen (HLA). Finally, they considered a test that looks at the balance of the response between two subsets of $\mathrm{CD} 4$ T helper cells (Th1 and Th2). (It is thought that the balance between Th1 and Th2 cytokine response is important in pregnancy.) Several immune therapies were also examined.

The review found that among all the tests and therapies offered, the only treatment that was validated by current research was aspirin and heparin for antiphospholipid syndrome in women with recurrent miscarriage; this treatment should be offered routinely to these patients, the review said.

In the case of antiphospholipid syndrome in recurrent miscarriage, the antibodies are thought to have a deleterious effect on embryonic implantation, trophoblast function and differentiation, and later in pregnancy, on placental thrombosis.

Professor Lesley Regan, who carried out the review on behalf of the Royal College of Obstetricians and Gynaecologists' scientific advisory committee, said: "The failure to conceive or carry

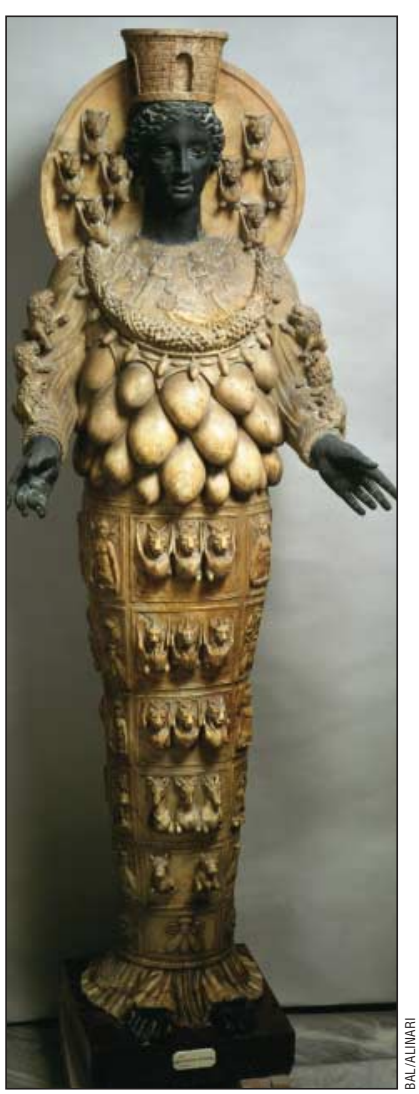

Praying to Artemis of Ephesus, a goddess associated with fertility, might be as useful as undergoing some of the fertility tests offered on the internet

a baby to term can cause considerable distress to a couple. It is a major concern to clinicians in the UK that patients are turning up to appointments armed with information downloaded from the web and wanting these unvalidated immunological tests.

"It is clear that the advice given on many sites is strongly influenced by the personal prejudices of doctors practising non-evidence based medicine. Much of the data they provide has never been exposed to the rigorous scrutiny of peer review. The couples are emotionally vulnerable, and there is currently no scientific evidence to justify the use of these tests and treatments."

Immunological Testing and Interventions for Reproductive Failure is available at www.rcog.org.uk mainpages.asp?pageid $=111$ 